\title{
FOUCAULT Y EL ÉTHOS EDUCATIVO
}

\author{
JORGE DÁVILA \\ Universidad de los Andes, Mérida, Venezuela
}

\begin{abstract}
ResUMEN: Se propone una manera de leer y entender la obra de Michel Foucault para una transformación posible del modo de ser del maestro y del modo de ejercer su acción pedagógica. El énfasis de la propuesta está en tener como guía directiva de la lectura de la obra los últimos cursos del filósofo en el Colegio de Francia. La noción esencial de esa lectura es la del "maestro de vida" como encarnación del éthos apropiado y auténtico para esa figura del maestro.

Palabras claves: Ética del educador. Decir verdad (parresía). Filosofía histórico-crítica.
\end{abstract}

El provecho para un educador que sea lector de la obra de Michel Foucault puede ser grande. Puede ser grande en extensión, sin duda. La obra de Foucault recorre una enorme porción de los ámbitos del conocimiento que han forjado la cultura occidental. También la obra de Foucault tiene un recorrido historiográfico que cubre desde el tiempo de la antigüedad grecolatina hasta nuestra propia contemporaneidad. La educación tendemos a verla como un fenómeno cultural propio de la historia de Occidente, así el educador que es lector de Foucault puede esperar del pensamiento de este filósofo, al menos, un enriquecimiento de sus conocimientos sobre el contexto en el que suele ubicarse el fenómeno educativo. Pero puede ese lector interesarse mayormente en contenidos más específicos sobre el propio fenómeno educativo, y no sólo relativos al contexto de su comprensión. Si este último es el caso, el provecho tal vez sea más limitado. Al menos así lo puede concebir quien elabora para sí mismo la visión del trabajo intelectual de Foucault como un trabajo crítico e histórico referido a los procesos de control y dominación social, política y cultural que se han desplegado en la civilización occidental 
a lo largo de siglos. Igualmente limitado será el provecho para el educador lector de Foucault que ha construido una comprensión del pensamiento de Foucault como un pensamiento que se obstina en diagnosticar el estado del presente de la sociedad occidental descifrando los mecanismos discursivos a través de los cuales el mismo pensamiento es tomado prisionero de sus propias trampas. Y aún más limitado será el provecho para el educador que busca con afán orientaciones pragmáticas para una reforma escolar que siga manteniendo la forma básica de la escuela moderna y contemporánea. Pensando en todos estos posibles educadores lectores de Foucault, en este breve ensayo quiero argumentar a favor de la hipótesis de que el gran aporte del pensamiento de Foucault para un educador, el maestro-lector de Foucault, consiste en una vital ayuda para la comprensión de su éthos, de su propio carácter como educador auténtico.

Piense el maestro-lector en dos modos de asumir la lectura de los textos de Foucault: 1) He de descifrar y ordenar en esos textos el material para mejorar mi comprensión sobre el hecho educativo; 2) He de buscar que esos textos labren en mí una transformación de mi (modo de) ser maestro. Como resulta evidente, la primera modalidad supone una actitud de desprendimiento vital en relación con los textos; el impacto de ello sólo será en el espacio cognoscitivo del lector. Esa modalidad de lectura es la típica del lector que busca auxilio en el autor para la elaboración de un trabajo académico que le compromete con una tarea; una tesis de postgrado, por ejemplo. La segunda modalidad supone algo más. No anula la primera modalidad, no la niega, ni tampoco podemos decir que busca superarla. Su interés también es cognoscitivo. Sólo que la atención fundamental del lector se centra en las modificaciones que la lectura -su comprensión, su análisis, su trabajo hermenéutico de los textos- puede ejercer sobre su propio modo de ser. En esta modalidad de lectura, el educador lector no se distancia del texto colocando como intermediario el interés meramente cognoscitivo. Todo su interés está marcado por la utilidad que aporte la comprensión del texto en la reestructuración del modo de vida del lector que es, efectivamente, maestro. Dicho de modo más directo: leer Foucault para ser uno mismo otro maestro.

En trabajos anteriores me he referido a este asunto (DÁVILA, 2006, $2007,2013)$. Pero me parece que allí mi discurso oscilaba entre las dos modalidades que termino de indicar, con cierta propensión a la primera modalidad. Rescataré de ello, sin embargo, esta idea:

El filósofo antiguo que privilegia en su ejercicio los principios de la vida verdadera, como otra vida posible, el 'maestro' que enseña esa vida, en y por 
su propia vida, que somete a prueba no sólo la verdad por la vida sino, más esencialmente, somete a prueba la vida por la verdad, guiado por el decir verdadero del parresiastés, ése es el tipo puro ideal del maître de vie. Es en él y sólo en él en quien puede encarnarse la 'ética de la palabra' (DÁVILA, 2006, p. 167).

Como es bien conocido, las últimas investigaciones de Foucault aportaron una nueva y lúcida interpretación de la filosofía antigua en cuanto discurso sobe la verdad. Si toda la investigación foucaultiana, como él mismo reconoció, fue un trabajo del pensamiento sobre los juegos de veridicción, los juegos de decir la verdad, sus últimos trabajos se enrumbaron hacia la forma constructiva de posibilidades para la conformación de unos juegos de verdad que se postulan sobre la base de la comprensión de una vida con sentido. Es decir, que esas posibilidades deben encarnar una postura ética, o mejor dicho, deben ser formas de vida que se constituyen en torno a la misma constitución de un éthos que obedece al empeño de hacer del juego de la existencia una ética del decir verdadero. No se trata pues de la conformación de un código para el comportamiento, sino más bien, de la comprensión de los juegos de la verdad que se juegan como punto reflexivo permanente de la práctica social. La incursión reflexiva de Foucault en la filosofía antigua saca a la luz una manera de entender el ejercicio del pensamiento, la actividad filosófica, como una práctica "educativa", mejor: una práctica paidética, en la que el filósofo es, no más ni menos, un "maestro", un maestro de vida. En ese sentido, como he sugerido en los otros trabajos referidos, esa figura del maestro de vida se opone al maestro de verdad, de acuerdo con la importante noción que construyera Marcel Detienne. Eso quiere decir, en pocas palabras, que a diferencia del maestro de verdad, para quien los juegos de la verdad tienen su sentido en un fondo que escapa al logos, a la razón, el maestro de vida busca afanosamente descifrar el sentido bajo el ejercicio del pensamiento siempre en el mismo dominio del pensamiento en cuanto es ejercicio de la razón.

¿Quiero decir entonces que un maestro-lector de Foucault, para ser y hacerse él mismo otro maestro, se hará un maestro de vida, habrá de convertirse en un filósofo? No me parece que esa ha de ser la lectura de mi hipótesis. Más bien ésta: que todo maestro pueda encontrar el camino para su transformación en un maestro de vida transformando precisamente su modo de ser maestro; es una transformación ética de la misma práctica social de la enseñanza lo que se pone en juego y no una transformación exclusivamente individual. No niega esta hipótesis que el maestro se constituya también en filósofo, porque de hecho tendrá que ocurrir. Pero el despliegue de la transformación 
aquí sugerida se da en el espacio preciso de la práctica social del ejercicio de la educación. Es esto lo que, hoy día, me parece un tanto confuso en lo que quise expresar con la noción de "vida académica" en mis otros escritos. Y creo que cuanto en ese entonces tenía en mente estaba restringido, sin necesidad, a la práctica social del trabajo universitario (filosófico, artístico y científico). La pregunta entonces es: ¿Cuál es esa transformación ética de la práctica social de la enseñanza, de hoy día, donde la figura del maestro se transforma en la de un maestro de vida? Intentemos dar respuesta.

'Maestro de vida' es una noción opuesta, históricamente, a la noción de 'maestro de verdad'; vida (bios) y 'verdad' (alétheia). La genealogía de Foucault muestra, con fino detalley en el horizonte una mejor comprensión de la formación y las mutaciones del pensamiento filosófico, las características diferenciadoras del maestro de vida en relación con las del maestro de verdad. La noción de maestro de verdad quedó perfectamente expuesta en la obra de Detienne:

Funcionario de la soberanía o elogiador de la nobleza guerrera, el poeta es siempre un 'Maestro de Verdad'. Su 'Verdad' es una 'Verdad' asertórica: nadie la pone en duda, nadie la prueba. 'Verdad' fundamentalmente diferente de nuestra concepción tradicional, Alétheia no es la concordancia de la proposición con su objeto, tampoco la concordancia de un juicio con otros juicios; no se opone a la 'mentira'; lo 'falso' no se yergue de cara a lo 'verdadero'. La única oposición significativa es entre Alétheia y Lethé. En este nivel de pensamiento, si el poeta está verdaderamente inspirado, si su verbo se funda sobre un don de videncia, su palabra tiende a identificarse con la 'Verdad' (DETIENNE, 1967, p. 27)

Portador de la Verdad, el maestro de verdad en la antigüedad es portador de una palabra mágico-religiosa transmutada en un logos racional aún dependiente de rasgos propios de la "Verdad" asertórica del poeta, del adivino o del rey de justicia. Foucault nos muestra que es la figura del parresiasta la que romperá las amarras del anclaje que tenía la palabra poética, la de la remembranza que combate el des-olvido, que juega con y contra Lethé, esa potencia que representa el olvido, más que el ocultamiento, potencia que es también No che. El maître de vie que representa el filósofo parresiasta surgió en oposición radical al aedo maître de verité. Tal oposición fue radical por el desplazamiento, en el fundamento del juego de la verdad, de la constitución del modo de ser, del éthos.

¿Quién encarna aquella figura del maestro de verdad hoy día? Si prolongamos la línea del razonamiento genealógico de Foucault en relación con el pensamiento filosófico, esa figura en el presente tendría que 
corresponder a los cultores contemporáneos del ejercicio de la palabra y del conocimiento que fue propio de los modos de decir verdad de la profecía, de la sabiduría y de la técnica. Recordemos las distinciones básicas que legó Foucault en su curso de 1983 en el Colegio de Francia: el parresiasta aparece en neta distinción de otros tres personajes que también practican un cierto decirverdad; ellos son: el profeta, el sabio y el técnico/'profesor', siendo considerado el retórico como un caso aparte de este último. Son personajes cuyos modos de palabra verdadera toman la forma enigmática, apodíctica y demostrativa, respectivamente. De manera que la parresía se distinguirá con mayor precisión de la palabra no sólo del maître de verité -el de la antigüedad, más cercano al personaje del sabio y del profeta, cuya palabra se expresa a través de la profecía y la sabiduría-, sino también de la palabra propia de la techné(aún la referida al bios) que toma la expresión de la enseñanza. Esas tres modalidades (profecía, sabiduría, técnica), distintas al modo de veridicción parresiasta, ocupan un dominio del discurso en el que predomina, correspondiendo a cada caso, la inquietud por el destino, la inquietud por el Ser o la inquietud por la técnica del mundo, mientras que, por su parte, el dominio del discurso parresiástico será más bien el éthos (FOUCAULT, 2009, curso del 10 febrero). Me parece que al leer con esta perspectiva los textos críticos de Foucault, esos textos que ya muchos intérpretes en el campo filosófico-pedagógico han asimilado a la comprensión de la génesis de la pedagogía moderna (DE FREITAS, 2013; GALLO, 2008; TERNES, 2006; CASTRO, E., 2006; RUNGE, A., 2003), se puede comprender que las últimas investigaciones de Foucault permiten apuntar hacia elementos que constituyen bases para una apropiación de la noción de maestro de vida que se oponga a lo que podemos llamar 'actualización renovada' del maestro de verdad. Por 'actualización renovada' quiero decir las formas degradadas del modelo de maestro de verdad que han dominado en la modernidad. Quiero explicar esto último un poco más.

Una cierta figura transformada del maestro de verdad puede entenderse como la idea inspiradora de la práctica pedagógica en la modernidad reciente. El maestro, el profesor, estuvo Ilamado a ser un "carácter", para usar la noción acuñada por Alasdair MacIntyre (Maclntyre, 2007), que expresa, en su acción social de ejercicio de la educación, una base fundamental de la práctica de la vida con sentido. Ese llamado descansaba, por lo esencial, en el apego al ejercicio de la racionalidad práctica y sobre la base del despliegue del conocimiento aportado por el avance de la ciencia y la técnica. En ese despliegue se renueva el espíritu que guiaba el decir verdadero (profético, sabio y técnico) de la antigüedad colocándolo 
bajo el dominio superior del ejercicio de la razón como expresión cabal del decir verdadero parresiástico. Este llamado, sin embargo, fue rápidamente desplazado por la fuerza de la racionalidad instrumental $y$, en la sociedad altamente industrializada, cedió apresuradamente su espacio al desarrollo, en su lugar, de toda la tecnología pedagógica, de formación de docentes y de institucionalización del espacio escolar de acuerdo con los principios, métodos y técnicas provenientes del encauzamiento disciplinario y biopolítico tan bien descritos por Foucault. De manera que la figura del maestro de verdad, podemos decir, únicamente sirvió de invocación -por su apego a la pretensión del decir verdadero- a la figura del maestro de la modernidad, una invocación queriendo instituir un maestro de verdad apegado al ejercicio racional (científico y técnico). Esa figura, en su inmensa fragilidad, fue apenas pasajera. Al querer transformar el fondo de la techné o de la profecía o de la sabiduría por el fondo del ejercicio de la racionalidad auténtica de la modernidad, fue cediendo el paso a un fondo ciego que invoca la ciencia y la técnica sin su verdadero carácter racional, su carácter práctico.

Ahora bien, la misma figura del maestro, no obstante, pudo ocupar en la sociedad industrializada temprana el espacio de una referencia para el sentido de la vida común (Maclntyre, 2007, p. 27-28); un sentido de la vida en cuyo centro se coloca la constitución del individuo como ciudadano, no sólo de la nación sino como ciudadano miembro de la comunidad racional de la humanidad, 'ciudadano del mundo'. Este espacio en muy poco tiempo dio paso a la ocupación por una versión de la figura del maestro desarraigado del espacio directivo de la vida social. Su función se subordina a una función más bien secundaria, la de una suerte de obrero fabril cualquiera, que labora con un "material" que debe transformarse en "recurso humano"; un recurso más que se maneja como todo recurso del mercado, vino a constituir el centro del interés de la existencia de la figura del maestro. Ya en el presente, el papel formador de ciudadanos del maestro deviene, en el país emblemático de la sociedad altamente industrializada, una formación para "ciudadanos" disponibles para la guerra; así lo afirman algunos autores estadounidenses, por ejemplo Kerry Burch afirma: Tenemos "un orden educativo que se presenta a sí mismo como eminentemente racional pero que, en el fondo, es irracional" y en el cual "las escuelas, en su campo de acción y no sólo por omisión en el currículo, han servido durante décadas como campo de cultivo fundamental para la reproducción de sumisos ciudadanos-para-la-guerra" ${ }^{11}$ (BURCH, 2009, p. 75, 77). Finalmente, atrapada esa figura por el desorden discursivo que mezcla pedagogía y tecnología gerencial, fue quedando una 
estructura disciplinaria y burocratizada sobre la que comenzó una danza sin fin del comportamiento desvariado y emotivo que perdió el rumbo de indicar al aprendiz una forma elemental de vida con sentido.

Es así como aparece, con inusitada, intensiva e invasiva fuerza una actitud que se halla sojuzgada a la ciega obediencia a la técnica, a la disciplina, al maquinismo y, más esencialmente, a la negación, por ausencia, de todo fondo de sentido. De manera que presenciamos una mutación que se caracterizó por el trastrocamiento del fundamento mismo de las dos versiones de la figura del maestro de verdad: no olvidemos que, por una parte, el maestro de verdad de la tradición labrada desde la antigüedad, deja el fondo en un 'misterio incomprensible', lo que llama a una actitud de respeto; por otra parte, el maestro de verdad del proyecto de la modernidad, el más auténtico, el que dio paso a la estelar pero efímera figura del maestro como guía ilustrado de la constitución moral de la sociedad moderna, se constituye sobre el fondo del ideal explícito de la vida guiada por el ejercicio de la razón. En el lugar de esas dos figuras del maestro, con su fundamento constitutivo de una vida con sentido, lo que apareció, en la modernidad dominada por la incomprensión de la auténtica racionalidad, es una triste caricatura del maestro de verdad que hoy es dominante -un maestro del mentir, del disimulo, una figura más del 'olvido' de todo fondo posible para una vida con sentido. Es esto lo que llamo la 'actualización renovada' del maestro de verdad.

La figura de un (nuevo) maestro de vida se puede oponer a la figura dominante de quien hemos llamado 'renovado maestro de verdad'. Ahora bien, ese maestro de vida es el que puede ser apropiado por el maestro-lector de Foucault al que me refería al comienzo de este ensayo. En tal apropiación se constituye el maestro que encuentra el camino para su transformación, forjada por él mismo, de su modo de ser maestro; es una transformación ética de la misma práctica social de la enseñanza lo que pondrá en juego y no una transformación exclusivamente individual, al estilo de cómo se suele entender un trabajo ético que se define por el mero estudio de la ética como disciplina del conocimiento. Es entonces una lectura de la obra de Foucault que sólo adquiere su mayor significado en la medida en que se convierte en práctica de la labor de maestro. Leer pues los trabajos de Foucault, especialmente los de sus últimos cursos en el Colegio de Francia (desde 1981 hasta 1984), como formación ética de un maestro (maestro de vida que es maestro de educación básica o secundaria) exige, a nuestro modo de ver, poner en práctica una transformación del modo de ser de ese maestro en la acción escolar. Así puede él entender y vivir mejor la 
vital experiencia de pensamiento del filósofo que lee, la experiencia de su 'vida filosófica', la experiencia de su pensar que se hace uno y el mismo con el pensar del maestro-lector. No se quedará esa lectura, al menos no con conformidad, en la comprensión del impacto del profundo contenido de la obra referido al decir-verdadero y al coraje de ejercerlo en la vida educativa. El maestro-lector seguramente tendrá que decir y decirse lo equivalente, en su caso -el de su concreta sociedad, la de su país, la de su nación donde desempeña su labor de maestro-, a una afirmación como esta: "la parresía representa un sólido principio pedagógico para alcanzar el coraje democrático en la acción, un principio extremadamente necesario hoy día para contraponerse a los debilitadores efectos de la educación manejada por el mercado y la obstinada tenacidad del éthos guerrero estadounidense" ${ }^{\prime 2}$ (BURCH, 2009, p. 80). El maestro-lector se dirá aún más, hará aún más: hará del ejercicio parresiástico el conductor vital de su práctica como educador para la recuperación del sentido de la vida.

Entenderá el lector que todo cuanto en este ensayo se dice no son más que aproximaciones muy rudimentarias de algunos hilos que conducen a decir qué es la práctica escolar para enseñar a vivir. Ciertamente. Esta pequeña reflexión está cargada de una experiencia vivida por el autor en los últimos siete años de compromiso en la enseñanza no universitaria, pero desde ella. Una experiencia escolar que descansa en un cierto ejercicio parresiasta que en otra parte hemos resumido así: lo que hacemos maestro de vida y alumno de cualquier "ejercicio del conocimiento" ha de ser indisoluble, en la vital experiencia del aprendizaje, del disfrute simultáneo del lenguaje, de la memoria familiar, de los conocimientos históricos, geográficos, de los objetos útiles cotidianos que nos rodean, del ambiente y del espacio, de los conocimientos de aritmética/geometría/lógica/álgebra, de la ciudad y su gente, de la práctica del arte y la música, de la relación de confianza entre el maestro y el alumno, etc. Es ese disfrute, ese sabor del saber, ese gusto por la verdad el centro de la atención y el cuidado que se presta en una escuela en donde nos empeñamos en que puedan existir escuelas que enseñen a vivir. Es el propósito de un proyecto educativo en el que, de fondo, se quieren mostrar las exigencias inevitables a las que está sometida la figura del Maestro si aún queremos que se mantenga como una figura que sea clave para la construcción de una vida con sentido. Tales exigencias son de una magnitud y una densidad que sólo lucen como aspiración para cualquier maestro en el mero discurso; pero en verdad, las acciones que requiere sobrepasan la disposición ordinaria que la sociedad actual exige y son francamente 
contrarias al sentido ordinario del éxito. Por eso, el proyecto se entiende a sí mismo como una revolución educativa que tiene más claro en su horizonte el fracaso que el éxito. Al decir fracaso, entendemos que las amenazas acechan de tal modo y con tal vigor que hacen del proyecto una experiencia vital como esas que calificamos como de última oportunidad; vivir cada día de la escuela como si fuera el último.

\section{FOUCAULT E O ETHOS EDUCATIVO}

Resumo: Propõe-se aqui, neste artigo, uma maneira de ler e entender a obra de Michel Foucault para uma transformação possível do modo de ser professor e do modo de exercer sua ação pedagógica. A ênfase da proposta está em guiar a leitura de sua obra a partir dos últimos cursos ministrados pelo filósofo no Collège de France. A noção essencial dessa leitura é a do "mestre de vida" como encarnação do ethos apropriado e autêntico para essa figura do professor.

PalAVRAS-ChAVE: Ética educacional. Discurso de verdade (parésia). Filosofia histórico-crítica.

\section{FOUCAULT AND THE EDUCATIONAL ETHOS}

ABSTRACT: This study proposes a way of reading and understanding Foucault's works in order to bring about a possible transformation of the teachers' way of being and how they carry out their pedagogical action. The proposal focuses on guidelines for reading his work, using his final courses at Collège de France as a basis. Crucial to this reading is the notion of "master of life", as the incarnation of the appropriate and authentic ethos for the teacher figure.

KEYWORDS: Education ethics. Truth discourse (parrhesia). Historical-Critical philosophy.

\section{NOTAS}

1) Traducción de: An educational order that presents itself as eminently reasonable but is irrational at its core [...] the schools, largely though not exclusively through curricular omission, have for decades served as breeding grounds for reproducing compliant citizen-warriors. 
2) Traducción de: [...] parrhesia represents a sound pedagogical principle for achieving democratic courage in action, a principle sorely needed today to counter the debilitating effects of a market-driven education and the dogged tenacity of the American warrior ethos.

\section{REFERÊNCIAS}

BURCH, K. Parrhesia as a principle of democratic pedagogy. Philosophical Studies in Education, Ohio (USA), v. 40, 2009, p. 71-82.

CASTRO, E. Leituras da modernidade educativa. Disciplina, biopolítica, ética. In: KOHAN, W.; GONDRA, J. (Org.). Foucault 80 Anos. Belo Horizonte: Autêntica, 2006. p. 63-78.

DÁVILA, J. Ética da palavra e vida acadêmica. In: KOHAN, W.; GONDRA, J. (Org.). Foucault 80 Anos. Belo Horizonte: Autêntica, 2006. p. 151-176.

. Michel Foucault: ética de la palabra y vida académica. Utopía y Praxis Latinoamericana, Maracaibo, Venezuela, año 12, n. 39, oct.-dic. 2007, p. 107-132.

. Re(des)encuentros de Foucault con Spinoza. In: MUCHAIL, S. et al. O Mesmo e o Outro. 5 anos de Historia da Loucura, Belo Horizonte: Autêntica, 2013. p. 315-340.

DE FREITAS, A. A parresía pedagógica de Foucault e o êthos da educação como psicagogia. Revista Brasileira de Educação, v. 18, n. 53, abr.-jun. 2013, p. 325-338.

DETIENNE, M. Les Maîtres de Verité en Grèce Archaïque. Paris: Maspero, 1967.

FOUCAULT, M. Le Courage de la Vérité: le gouvernement de soi et des autres, II. Cours au Collège de France 1983-1984. Paris: Gallimard: Seuil, 2009.

GALLO, S. Foucault: (re)pensar a educação. In: RAGO, M.; VEIGA-NETO, A. (Org.). Figuras de Foucault. 2. ed. Belo Horizonte: Autêntica, 2008. p. 253-260.

MACINTYRE, A. After Virtue. A Study in Moral Theory. 3. ed. Indiana: University of Notre Dame Press, 2007.

RUNGE-PEÑA, A. Foucault o de la revaloración del maestro como condición de la relación pedagógica y como modelo de formación. Revista Educación y Pedagogía. Medellín, Colombia, v. 15, n. 37, 2003, p. 219-232.

TERNES, J. Foucault, a escola, a imprudência do ensinar. In: KOHAN, W.; GONDRA, J. (Org.). Foucault 80 anos. Belo Horizonte: Autêntica, 2006. p. 93-104.

Jorge DÁVILA é doutor em Ciências Sociais pela École de Hautes Etudes en Sciences Sociales. Pesquisador do Centro de Sistemología Interpretativa, Universidad de Los Andes, Mérida, Venezuela.

E-mail: joda@ula.ve 